\title{
A Atuação dos Sujeitos Processuais na Cooperação Judiciária Nacional: Entre o Dever do Juiz de Realizar e o Direito da Parte de Participar
}

\author{
The Acting that Procedural Subjects the National Judicial Cooperation: Between the Judge's \\ Duty to do and the Party's Right to Participate
}

Nilsiton Rodrigues de Andrade Aragão'

${ }^{1}$ Universidade de Fortaleza - UNIFOR, Brasi

\section{Resumo}

O presente artigo analisa a cooperação judiciária nacional com foco na atuação dos sujeitos processuais. Inicialmente, serão abordadas as potencialidades e limites do dever de cooperação, destacando-se as recusas aceitas para interação dos juízes. Em relação às partes, dentre as medidas a serem observadas, destaca-se a necessidade resguardar a garantia constitucional do contraditório, em face do direito de influência, para que os sujeitos processuais possam participar efetivamente de sua construção, bem como impugnar os atos realizados.

Palavras-chave: Cooperação Judiciária; Dever de Cooperação; Participação das Partes

\section{Abstract}

This article analyzes the national judicial cooperation focusing on acting that procedural subjects. Initially, the potentialities and limits of the duty of cooperation will be addressed, highlighting the accepted refusals for the interaction of the judges. In relation to the parties, among the measures to be observed, there is an increased need for the constitutional guarantee of the adversary, in view of the right to influence, so that procedural subjects can participate effectively of its construction, as well as contesting the acts performed.

Keywords: Judicial Cooperation; Duty of Cooperation; Stakeholder Participation

\section{Introdução}

A busca por uma eficiência processual está entre as diretrizes do Código de Processo Civil, para atingir tal propósito foram incluídos no ordenamento jurídico diversos instrumentos processuais com o intuito de diminuir o formalismo exacerbado e a burocracia desnecessária. Inclui-se entre esses institutos a cooperação judiciária nacional, voltada a otimizar a interação entre juízos.

Nesta revista, na qual se presta homenagem à memória jurídica do Prof. José Joaquim Calmon de Passos, um dos maiores ícones do direito processual brasileiro, impõe-se analisar a cooperação judiciária sob a ótica do seu pensamento. Entre os pilares da sua doutrina é possível destacar a crítica à instrumentalidade das formas e da ampliação dos poderes do juiz .

De fato, a cooperação judiciária é um instituto marcado pela atipicidade em diversos níveis. A maleabilidade procedimental é uma característica que lhe permite uma aplicação mais larga, mas é

1 PASSOS, José Joaquim Calmon de. Ensaios e artigos - V.1. Salvador: JusPodivm, 2014, pág. 34. 
também um de seus aspectos de fragilidade, pois traz em si um risco de que seja um ambiente fértil para o abuso e para a insegurança. Dessa forma, é preciso dimensionar os limites e estabelecer balizas para a flexibilidade formal e a ampliação dos poderes do juiz trazidas pelo instituto sem que acarretem insegurança jurídica.

Existe aqui uma questão quase paradoxal. Se, por um lado, é importante manter o procedimento de cooperação mais aberto, para garantir a flexibilidade necessária à adaptação do instituto a cada necessidade de interação dos casos concretos, por outro, é importante apresentar regras procedimentais básicas para estimular as primeiras utilizações do instituto e dar mais segurança aos atos processuais.

Na busca desse equilíbrio entre a eficiência processual e a segurança jurídica, o presente trabalho se propõe a analisar a forma de atuação dos sujeitos processuais, que é sensivelmente alterada pela cooperação judiciária nacional, na medida em que permite um diálogo mais direto e informal entre os juízos, inclusive com alteração e modificação da competência dos mesmos.

Essa mudança implica também na forma de diálogo entre os magistrados e as partes dos processos envolvidos na cooperação. É preciso avaliar a manifestação do contraditório e da cooperação na possibilidade de influência das partes na construção e no controle da cooperação.

\section{Dever de cooperação}

Em linhas gerais, a cooperação judiciária nacional consiste em um poder/dever de ampla interação entre juízos pelos meios mais eficazes para possibilitar a gestão adequada e eficiente de atos processuais ${ }^{2}$.

A cooperação entre juízos não é propriamente uma novidade, mas não era disciplinada de forma estruturada no Código anterior. Na medida em que o Código atual dedica um capítulo específico e passa a tratá-la como um "dever", a perspectiva de interação entre os juízos é sensivelmente alterada ${ }^{3}$.

Sobre essa questão, duas posições começam a se formar. A primeira, trata a cooperação como um faculdade, atribuindo ao juiz liberdade na escolha de quando e como cooperar. ${ }^{4}$ A segunda, ressalta o caráter cogente da cooperação judiciária por envolver valores relevantes ao Poder Judiciário que devem se sobrepor à vontade do isolada dos magistrados. ${ }^{5}$ Logicamente, a questão não é tão simples que possa ser completamente abordada nessas duas posições antagônicas, mas elas ajudam a compreender a divergência sobre a matéria.

2 Na definição de Luiz Henrique Volpe Camargo, trata-se do "conjunto de atos de gestão adequada de processos e intercâmbio processual entre juízos diversos para prestação jurisdicional de forma plena, econômica, racional e eficiente" (CAMARGO, Luiz Henrique Volpe. A centralização de processos como etapa necessária do incidente de resolução de demandas repetitivas. 2017. Tese (Doutorado em Direito) - Pontifícia Universidade Católica de São Paulo, São Paulo, 2017, p. 303).

3 Maria Gabriela Silva Campos Ferreira explica que: "O dever de recíproca cooperação encartado no art. 67 do CPC do CPC decorre do princípio da unidade da jurisdição e funciona como estímulo para que os órgãos jurisdicionais cooperem entre si na condução do processo. É um reforço para que juízes de quaisquer instâncias e Justiças atuem conjuntamente na condução de litígios que surjam a partir de um mesmo conjunto de fatos ou que envolvam idêntica questão de direito" (FERREIRA, Maria Gabriela Silva Campos. O compartilhamento de competências no processo civil: um estudo do sistema de competência sob o paradigma da cooperação judiciária. Salvador: JusPodivm, 2020, p. 129).

4 É o que defende José Eduardo de Resende Chaves Júnior: "É certo, contudo, que a cooperação não funciona sob o prisma da coação, pois ela demanda dos atores cooperantes um plus de energia colaborativa, que se incompatibiliza com a obrigatoriedade; basta que o juiz adote um enfoque mecanicista e formal para a cooperação não funcionar.” (CHAVES JÚNIOR, José Eduardo de Resende. Cooperação judiciária na justiça do trabalho. Revista do Tribunal Regional do Trabalho da $3^{\underline{a}}$ Região, Belo Horizonte, v. 61, n. 92, p. 107-130, jul./dez. 2015, p. 110).

$5 \quad$ Nesse sentido se posicionam Marinoni, Arenhart e Mitidiero: "De fato, embora o texto legal aluda a atos 'concertados', é evidente que essa prática não depende da 'boa vontade' dos juízes envolvidos. Não se trata de simples faculdade outorgada aos magistrados. Porque os juízes estão investidos de verdadeiros poderes-deveres, presentes situações de preservação da isonomia ou da eficiência da prestação jurisdicional, a concentração de atos deve ocorrer". (MARINONI, Luiz Guilherme; ARENHART, Sérgio Cruz; MITIDIERO, Daniel. Novo curso de processo civil: tutela dos direitos mediante procedimentos comum. 3ㅜㅡㄹ. Eão Paulo, Editora dos Tribunais, 2017, p. 74). 
Como não poderia ser diferente, a discussão se inicia na interpretação das normas que regulam a matéria. O Código de Processo Civil, em seu art. 67, estabelece o "dever de recíproca cooperação" aos órgãos do Poder Judiciário. A Resolução n.o 350/20 do CNJ não inovou muito nesse ponto, restringindose, em seu art. 20, a praticamente reproduzir o texto art. 67 do CPC, acrescendo apenas que o objetivo do dever de cooperação é "incrementar mutuamente a eficiência de suas atividades".

Ainda que a interpretação literal não seja a única a ser considerada, os limites semânticos do termo "dever" não podem ser ignorados ou demasiadamente flexibilizados. Portanto, o caráter cogente próprio de uma obrigação está presente.

Em contraponto, alguns autores ressaltam indicativos de facultatividade na lei ao passo que o art. 68 do CPC dispõe que "os juízos poderão formular entre si pedido de cooperação" e que a própria noção de "atos concertados", previsto no art. 69, IV e $§ 2^{2}$, traduz uma ideia de harmonização e deliberação conjunta incompatível com a definição de dever ${ }^{6}$.

Todavia, esses pontos não desnaturam a estrutura do dever de cooperar. É preciso entender que as duas normas referidas estão tratando de tipos de cooperação, não podendo ser interpretadas em desacordo com o art. 67 que trata a matéria de maneira geral.

Por essas razões iniciais, a cooperação judiciária será tratada como um dever. Isso não significa a inexistência de margem de atuações na qual uma cooperação pretendida não seja realizada. O dever de cooperação é colocado de forma geral, sem especificar seu alcance e limites nas diversas formas de manifestação. Esse dever geral precisa, portanto, ser paulatinamente densificado, caso a caso, pela argumentação jurídica e pelas decisões dos tribunais, para que se possa efetivamente compreender suas repercussões práticas.

\subsection{Fundamentos para a recusa}

Uma das primeiras diretrizes extraídas do dever de cooperação é a de que deve ser admita a recusa fundamentada, de modo que ele implica na obrigação de responder às provocação e de justificar as eventuais negativas. Por um lado, não é um dever acrítico de cooperar, como se um juiz devesse necessariamente fazer tudo o que o outro pretende. Por outro lado, a pretensão de cooperação não pode ser simplesmente ignorada, é preciso que o magistrado receba e analise a demanda, apresentando uma resposta fundamentada, ainda que negativa.

Ressalte-se que não se trata de um mero juízo subjetivo ou discricionário do magistrado, é preciso uma fundamentação juridicamente válida para a recusa. O interesse envolvido na realização da cooperação não é do juiz, por mera comodidade ou conveniência sua. O interesse é do Poder Judiciário enquanto responsável pela prestação jurisdicional de forma eficiente. Por conseguinte, ainda que uma cooperação se apresente dispendiosa para um magistrado específico, ela pode representar um ganho significativo de rendimento para o Judiciário, o que imporá sua efetivação.

Sendo assim, impõe-se identificar quais fundamentos podem ser apresentados para a negativa da pretensão de cooperação. Logicamente, não há como construir um rol exaustivo de situações, pois sempre existirão questões administrativas, materiais e processuais que poderão ensejar circunstâncias não previstas. Isso não impede que se elenquem as principais situações admitidas.

O art. 267 do CPC, que trata das cartas, pode ser utilizado como parâmetro para esse estudo. Ele apresenta uma diretriz inicial para as hipóteses de recusa, sendo possível extrapolar as situações nele previstas para as demais formas de cooperação ${ }^{7}$. Daí se extraem as três primeiras justificativas para a recusa: I) a incompetência do juízo; II) a inobservância de requisitos legais; III) a dúvida acerca de sua autenticidade. Logicamente, esse dispositivo não exaure a matéria, existindo outras justificativas que

6 FONSECA, João Gustado Henrique de Morais. Cooperação Judiciária processual: histórico, teoria e prática. Rio de Janeiro: Lúmen Júris, 2019, p. 11.

$7 \quad$ Fredie Didier Jr. defende que a disciplina normativa das cartas serve de parâmetro para a solução de problemas dogmáticos da cooperação judiciária nacional (DIDIER JR., Fredie. Cooperação judiciária nacional: esboço de uma Teoria para o Direito Brasileiro. Salvador: Juspodivm, 2020, p. 79). 
também podem servir de fundamento para a rejeição à cooperação, dentre as quais pode-se indicar: IV) o objeto do ato afronta o Direito; V) a impossibilidade prática de realização do ato; e VI) a inconveniência da cooperação. Passa-se a analisar cada uma delas.

A primeira justificativa é a da incompetência para a prática do ato objeto da cooperação pelo juízo cooperante. Esse é um dos pontos centrais da discussão dos limites do instituto, pois a cooperação judiciária pode ensejar a alteração da competência. O art. 1o, I da Resolução n.․ 350/20 do CNJ foi expresso ao estabelecer que a cooperação judiciária deve observar "o princípio do juiz natural e as atribuições administrativas".

Isso não significa que qualquer pretensão de mudança de competência seja motivo para a recusa. A cooperação judiciária traz em sua essência uma ressignificação do princípio do juiz natural, algo que é facilmente constatado pelos próprios atos de cooperação previstos no CPC e na Resolução n. 350/20 do CNJ.

Com isso, altera-se a compreensão tradicional de competência única e exclusiva, pela qual uma vez definida a competência de um juiz para uma causa, seria ele o responsável único do primeiro ao último ato do processo ${ }^{8}$. Por força da cooperação passa-se a admitir a atuação conjunta de mais de uma juiz no mesmo processo, a modificação de competência para um ato específico, a alteração de uma regra de competência, a centralização de processos etc.

No caso da cooperação judiciária, os objetivos são concorrentes, pois o intuito é conjugar as competências e não excluir uma para a assunção de outra. Portanto, em regra não haverá conflito de competência. Todavia, podem existir situações de dúvida como, por exemplo, uma pretensão de definir por ato concertado um regra de competência que usurpa a competência de um terceiro juízo que não participa da concertação. Esse pode ser um fundamento para a recusa.

A incompetência absoluta é outro motivo possível para que a cooperação não seja realizada por aquele juízo. Tomando como exemplo a possibilidade de cooperação para a "definição do juízo competente para a decisão sobre questão comum ou questões semelhantes ou de algum modo relacionadas", prevista no art. $6^{\circ}$, V, da Resolução n.. 350/20, a própria norma prescreve que devem ser observadas as regras de competência absoluta previstas nos arts. 62 e 63 do CPC.

Para encerrar a análise dessa primeira razão para a recusa, vale salientar que o reconhecimento da incompetência de um juízo não significa necessariamente que a cooperação não ocorra, podendo ela ser encaminhada para outro juízo que detenha essa competência. Caberá ao magistrado demandado remeter a delegação, a solicitação ou a proposta de concertação ao juiz ou ao tribunal competente. Logo, a cooperação poderá ocorrer.

Como se percebe dessas rápidas questões apresentadas em relação à competência, é possível perceber que ela representa uma das principais e mais profundas questões da cooperação judiciária e, logicamente, não poderá ser exaurida nesse ponto específico. Ainda assim, o aprofundamento do tema violaria o recorte epistemológico proposto para esse artigo, motivo pela qual encerra-se a abordagem por aqui ${ }^{9}$.

A inobservância aos requisitos formais da cooperação é outro fundamento para a recusa à cooperação. Essa situação é mais comum no procedimento das cartas, uma vez que elas possuem um detalhamento formal específico. No entanto, esse fundamento perde importância nos demais instrumentos de cooperação em face da liberdade de formas que predomina neles.

8 É nesse sentido a análise de Antonio do Passo Cabral: "Essas características importam no fracionamento, divisão e isolamento mútuo entre os órgãos jurisdicionais, contribuindo para o engessamento das competências e falta de coordenação. Em nosso entendimento, esses traços são ineficientes e imobilizam as formas processuais sobre a competência, e portanto incongruentes com o que se espera da jurisdição contemporânea” (CABRAL, 2017, p. 33).

$9 \quad$ Nesse ponto, merece ressaltar a relevância da tese apresentada para o concurso de provas e títulos para provimentos do Cargo de professor titular de processo da UERJ pelo Professor Antonio do Passo Cabral, intitulada "Juiz natural e eficiência processual: flexibilização, delegação e coordenação de competências no processo civil”, um dos primeiros trabalhos a enfrentar o tema de forma direta, estruturada e com a profundidade necessária. 
É preciso destacar que essa justificativa não implica na recusa à cooperação, mas apenas em um adiamento do seu início para após a superação dos vícios formais identificados, caso sejam sanáveis.

A autenticidade do pedido de cooperação é um aspecto que deve ser analisado sempre que houver dúvida. É um aspecto que pode ganhar importância com os instrumentos atípicos de cooperação, que possibilitam meios mais informais de comunicação entre os juízos. A utilização de canais não institucionais pode acarretar dúvidas quanto à autenticidade, principalmente com o risco de clonagem ou hackeamento de meios de comunicação eletrônicos.

Ressalte-se que esse caso, igualmente ao anterior, não é hipótese de negativa da cooperação, mas somente de adiamento do seu início para após a conferência da autenticidade. Somente quando a falsidade for confirmada é que a negativa ocorrerá.

Outra questão que pode justificar a recusa à cooperação é o controle da legalidade por parte de um dos juízes cooperantes. Se o objeto da cooperação afrontar o Direito é dever do magistrado envolvido garantir a regularidade da ordem jurídica, recusando sua prática ${ }^{10}$. Em função da natural margem de interpretação dos limites da lei, esse ponto deixa sua análise mais aberta e eventualmente pode gerar dissenso entre os juízos envolvidos.

A impossibilidade prática de realização do ato é mais um dos motivos para a negativa de cooperação. Aqui a questão é de ordem prática. Ainda que o juízo queira cooperar não há como o ato ser por ele praticado por limitações físicas ou fáticas que inviabilizam sua consecução. É o que ocorre, por exemplo, na cooperação para a oitiva de uma testemunha que faleceu ou para a avaliação de um bem que pereceu. Não se trata de mera dificuldade, mas de inviabilidade concreta da execução do ato.

Um última situação que precisa ser analisada e que pode ser apresentada como justificativa para a recusa da cooperação é a sua inconveniência. Esse motivo vai estar pautado em uma avaliação de custo-benefício da interação entre os juízos, diante do elevado dispêndio de tempo ou força de trabalho exigido para a sua consecução em relação ao baixo ganho que ela traga para a prestação jurisdicional ${ }^{11}$.

É importante reforçar que a conveniência do ato deve ser analisada na perspectiva do Judiciário e não unicamente de uma unidade jurisdicional específica. A cooperação poderá se justificar se trouxer eficiência ao conjunto de demandas judiciais, ainda que imponha um incremento de atividade a um ou alguns juízos.

A ineficiência da cooperação pode estar relacionada a aspectos específicos do instrumento de cooperação que se pretende utilizar. Assim, por exemplo, na centralização de processos repetitivos pode não ser aconselhável a reunião de processos que estão em etapas de desenvolvimento muito distintas pode retardar indevidamente a conclusão daqueles que já estavam em estágio mais avançado, o que contraria a essência do instituto.

Como se percebe, esse é o fundamento mais aberto e, por esse motivo, o que demanda maior atenção para construção de um conteúdo dogmático concreto e objetivo. Nesse ponto podem ser incluídos aspectos como a demanda excessiva de processos, a carência de força de trabalho, a pouca abrangência ou repercussão do objeto proposto, as dificuldades operacionais de sua efetivação etc.

\subsection{A variação de intensidade do dever de cooperação}

Em princípio, como se trata de um dever, uma vez demandada a cooperação ela deveria ser atendida, caso contrário deveria incidir uma sanção. A estrutura base desse tipo de norma não admite uma escala de intensidade.

10 Como adverte Edilton Meireles: “Mas, lógico, sem se olvidar que na prática de qualquer ato sempre há o juízo de legalidade”. (MEIRELES, Edilton. Cooperação judicial e poderes do juiz na execução conforme o CPC de 2015. Revista Jurídica LusoBrasileira, Lisboa, ano 4, n. 1, 2018, p. 193).

11 Fredie Didier Jr. Exemplifica dizendo que: "O juízo solicitado poderia, demonstrando o alto custo da diligência, recusar a prática do ato caso demonstrasse também que o objetivo pudesse ser alcançado por outro meio”. (DIDIER JR. Fredie. Cooperação judiciária nacional: esboço de uma Teoria para o Direito Brasileiro. Salvador: Juspodivm, 2020, p. 106). 
Todavia, como o dever é colocado de forma geral pelo legislador, é preciso definir suas manifestações específicas. Ao analisar o dever de cooperação em toda a amplitude e complexidade do instituto, percebe-se que não é possível aplicar uma lógica binária simples. Entender a dimensão do dever geral de cooperação exige uma verificação mais acurada de suas diversas formas de manifestação.

Fredie Didier Jr., por exemplo, trata a compulsoriedade da cooperação judiciária em níveis de intensidade distintos em cada um dos seus tipos, manifestando-se mais forte na cooperação por concertação, seguida pela cooperação por delegação e sendo menos intensa na cooperação por solicitação ${ }^{12}$. Essa construção está em consonância com o que vem sendo defendido neste artigo, mas é preciso desenvolver o tema para dar contornos mais concertos à verificação dos diferentes níveis da obrigação de cooperar.

Para compreender a escala de intensidade do dever é necessário estabelecer uma maneira objetiva de medir essa variação. A melhor forma de fazer isso é a partir dos fundamentos aceitos como legítimos para a recusa à cooperação em cada um desses tipos. Isso porque alguns fundamentos para justificar a não realização da cooperação podem ser aceitos em uns casos, mas não em outros. Compreendidas, ainda que rapidamente, algumas das principais justificativas para a recusa à cooperação no tópico anterior é preciso agora analisar quais delas podem ser utilizadas em cada um dos tipos de cooperação para, a partir daí, entender a diferença de intensidade entre os tipos de cooperação.

Inicialmente, analisando as cooperações por solicitação e por delegação é possível resgatar debates doutrinários sobre o cabimento da recusa nas cartas precatórias e de ordem, instrumentos tradicionais dos referidos tipos de cooperação.

Um definição comum é a que uma das características fundamentais da cooperação por delegação é a sua compulsoriedade, decorrente da subordinação hierárquica entre os juízos. Seguindo a lógica da métrica definida para medir o nível de compulsoridade da cooperação, conclui-se que a cooperação por delegação deve aceitar menos hipóteses de recusa do que a cooperação por solicitação.

Nesse ponto, é importante registrar que o art. 267 do CPC só prevê a recusa ao cumprimento nos casos da carta precatória e arbitral, omitindo-se em relação à carta de ordem. Esse seria um sinal da compulsoriedade da cooperação por delegação. Uma primeira corrente doutrinária entende que essas hipóteses de recusa não são aplicáveis às cartas de ordem, portanto, não abrangem a cooperação por delegação ${ }^{13}$. No entanto, a corrente contrária parece ser a mais adequada ${ }^{14}$. Tomando por base as hipóteses previstas no art. 267 (incompetência absoluta, irregularidade formal ou falsidade), percebe-se que todas elas devem ser aplicadas à delegação tanto quanto à solicitação. Da mesma forma, a afronta ao Direito e a impossibilidade prática de realização do ato também devem ser aplicadas a todas as hipóteses de cooperação, inclusive para a cooperação por delegação.

O fato de a demanda por cooperação ter origem em um órgão jurisdicional de hierarquia superior não tem o condão de tornar qualquer dessas questões irrelevantes no caso concreto. A ordem de um ministro ou de um desembargador a um juiz não pode alterar uma regra de competência absoluta, não pode afastar uma exigência formal da lei, não faz presumir de forma absoluta sua autenticidade, não torna lícito o ilícito e não faz do impossível possível. Portanto, nesses pontos o dever de cooperar na delegação e na solicitação não difere.

Resgatando o rol de justificativas de recusa anteriormente apontado resta analisar o fundamento da inconveniência da cooperação. Em princípio, somente essa justificativa não poderia ser utilizada no

12 DIDIER JR., Fredie. Cooperação judiciária nacional: esboço de uma Teoria para o Direito Brasileiro. Salvador: Juspodivm, 2020, p. 105/106.

13 "Em que pesem respeitáveis posições em direção contrária, pensamos que nessas hipóteses inviável a recusa, seja pela subordinação hierárquica do juiz ordenado, seja pelo juízo de delibação prévio ao exequatur exercido pelo órgão competente (artigo 105, inciso I, $i$, da Constituição)". (GAJARDONI, Fernando da Fonseca; DELLORE, Luiz; ROQUE, Andre Vasconcelos; OLIVEIRA JR., Zulmar Duarte de. Teoria Geral do Processo: parte geral: comentários ao CPC de 2015. 3. ed. Rio de Janeiro: Forense; São Paulo: MÉTODO, 2019, p 219).

14 Em que pese o grau maior de impositividade da carta de ordem, que pressupõe superioridade hierárquica, penso que também ela pode eventualmente ser recusada. Exemplo disso: uma ordem manifestamente ilegal. (CRAMER, Ronaldo. Comentários ao art. 267. Comentários ao novo Código de Processo Civil. coordenação Antonio do Passo Cabral, Ronaldo Cramer. - 2a ed. Rio de Janeiro: Forense, 2016, p. 417). 
caso de cooperação por delegação, circunstância que marca o nível mais elevado da compulsoriedade. Não importa, se o juiz ao qual foi delegado o cumprimento de um ato está sobrecarregado, com desfalque na sua equipe ou que a relação de custo-benefício aponte a ineficiência da cooperação, ele deverá atender ao que fora determinado.

Avançando no estudo, falta tratar do dever de cooperação na concertação, o tipo de cooperação que ostenta o maior nível da compulsoriedade. O motivo dessa diferença de intensidade não é mesmo que difere os tipos de cooperação anteriormente tratados, não se refere à hierarquia, mas sim a autovinculação dos juízos.

Como essa cooperação não decorre de um pedido ou de uma ordem, mas de um acordo entre os juízos, as questões que poderiam ser levantadas como razão para a recusa são previamente analisadas. Se porventura alguma das hipóteses for verificada no caso concreto, a concertação não será efetivada, mas após ela ser firmada, como regra, tais questões não poderão ser reavaliadas para apresentação de recusa. É por isso que na concertação há um alto grau de vinculação.

Isso, no entanto, não implica que não possa haver recusa na cooperação por concertação. Aspectos não cogitados pelos magistrados no momento inicial ou fatos supervenientes que acarretem qualquer dos motivos já citados poderão ser suscitados. Mesmo assim, a probabilidade de recusa é significativamente menor e, por consequência, a sua compulsoriedade maior.

\subsection{Consequência para a violação ao dever de cooperação}

$\mathrm{O}$ art. 35, I, da Lei Orgânica da Magistratura (Loman), estabelece que é dever do magistrado "Cumprir e fazer cumprir, com independência, serenidade e exatidão, as disposições legais e os atos de ofício". Tratando-se o dever de cooperação de uma disposição legal expressa, a sua violação constitui inegável infração funcional do magistrado.

Resta avaliar a partir de que momento se verifica essa violação e qual a sua consequência.

Como visto anteriormente, diante da manifestação de interesse na cooperação judiciária o magistrado poderá apresentar uma justificativa para a recusa. Essa justificativa será avaliada pelo juízo que provocou a cooperação e, caso não se apresente adequada, se estará diante de um conflito que precisa ser superado. Destaque-se que a discordância em si não implica em violação ao dever de cooperação, somente se os motivos não forem considerados legítimos é que o dever de cooperação terá sido violado.

Todavia, o sistema não indica a quem compete essa análise de regularidade da recusa e esse é um ponto fundamental.

A Rede Nacional de Cooperação Judiciária tem um importante papel nessa atividade de superação de controvérsias entre juízos sobre a cooperação judiciária. O juiz de Cooperação, por exemplo, pode intermediar o diálogo entre juízes e ajudar na solução do dissenso, seja na aceitação da cooperação ou na conclusão de sua inviabilidade. Ainda que essa intervenção se mostre suficiente para grande parte dos casos, não será capaz de superar todas as situações.

Como se trata de um ato administrativo envolvendo dois juízos, é importante estabelecer um órgão como competente para analisar questionamentos quanto à validade da justificativa para a recusa em cooperar. Esse órgão poderá valorar a justificativa e declará-la legítima ou não.

Após essa definição, a manutenção da resistência apresentada à efetivação da cooperação configurará infração funcional que deverá ser apurada em procedimento específico perante a respectiva corregedoria. Após a instauração de sindicância e processo administrativo disciplinar correspondente, poderá acarretar a aplicação de uma das sanções administrativas previstas no art. 42 da $\operatorname{Loman}^{15}$.

15 Lei complementar n. 35/79, Art. 42 - São penas disciplinares: I - advertência; II - censura; III - remoção compulsória; IV - disponibilidade com vencimentos proporcionais ao tempo de serviço; $\mathrm{V}$ - aposentadoria compulsória com vencimentos proporcionais ao tempo de serviço; VI - demissão. 
Destaque, por fim, que a violação ao dever cooperação não apresenta consequências diretas para o processo, com exceção da perda de eficiência adicional que a cooperação traria. Portanto, a sua falta não acarreta perda ou prejuízo a ônus, poderes, faculdades e deveres processuais de qualquer dos sujeitos processuais.

\section{A participação das partes na construção da cooperação judiciária}

Passando a abordar a cooperação judiciária para além da perspectiva dos magistrados, merece atenção neste estudo a forma de participação das partes. O processo civil, pautado que é em uma base democrática e participativa, não pode excluir as partes dos debates que venham a interferir na solução dos seus conflitos, atribuindo ao juiz um protagonismo que reduza o necessário diálogo no desenvolvimento do processo ${ }^{16}$.

Essa participação deve ser analisada em duas momentos: I) no ato processual objeto da cooperação e II) na estruturação da própria cooperação.

Quanto ao primeiro aspecto, a participação das parte no ato processual objeto da cooperação é um aspecto imprescindível à sua regularidade pela própria imposição do contraditório. Cada ato deve respeitar sua forma de realização como se estivesse sendo realizado de forma isolada no próprio processo. Portanto, se a legislação prevê a possibilidade de manifestação ou participação da parte essa deverá ser necessariamente garantida ${ }^{17}$.

Assim, por exemplo, se a cooperação tiver por objeto a oitiva unificada de uma mesma testemunha em relação a fato que é comum a vários processos deve-se viabilizar que as partes de todos esses processos possam contraditar a testemunha, formular perguntas etc.

Já em relação ao segundo ponto, a questão é um pouco mais complexa. A construção e estruturação da própria cooperação judiciária cabe aos juízos cooperantes. Tem-se como premissa que a iniciativa da cooperação judiciária cabe aos magistrados, podendo realizar-se de ofício e, portanto, independentemente de qualquer provocação ou consentimento das partes. ${ }^{18}$

No entanto, isso não significa que se deva pura e simplesmente desconsiderar a posição das partes a esse respeito. Muito pelo contrário, as partes podem ter mais informações do que o próprio juiz sobre as possibilidades de cooperação, já que conhecem melhor o conflito e eventuais outras ações a ele relacionados. Nessa linha, a Resolução n.. 350/20 do CNJ, em seu art. 8º,$\S 4^{\circ}$, previu a possibilidade de provocação da cooperação pelas partes e pessoas naturais ou jurídicas, órgãos ou entidades especializadas, com representatividade adequada.

Definido o interesse em realizar a cooperação, seja por iniciativa do juízo, seja por provocação de algum interessado, o dever de cooperação entre os sujeitos do processo (art. 6. do CPC) impõe que o juiz dialogue com as partes sobre todas as questões relevantes, dentre as quais se destaca a cooperação judiciária. Não é possível tratar todas as formas de interação entre os juízos como mero desenvolvimento burocrático do processo, a ser tocado por impulso oficial e sem impacto na solução do mérito da demanda. A cooperação pode ser um fator que altere o curso do julgamento do mérito da demanda, o que revela indiscutível interesse das partes.

Nesse sentido, o caput do art. 9o da Resolução n.o 350/20 do CNJ prescreve que "Os juízos cooperantes, quando a complexidade da matéria recomendar, poderão intimar as partes a se manifestarem acerca do

$\overline{16}$ PASSOS, Jose Joaquim Calmon de. Revisitando o Direito, o Poder, a Justiça e o Processo. Salvador: JusPodivm, 2012, p.

214.

17 Como adverte Fredie Didier Jr.: “a concertação deve permitir que os sujeitos processuais dos casos envolvidos possam participar da formação do convencimento do juízo centralizados - o poder de influência, conteúdo do contraditório, não pode ser eliminado”. (DIDIER JR. Fredie. Cooperação judiciária nacional: esboço de uma Teoria para o Direito Brasileiro. Salvador: Juspodivm, 2020, p. 104).

18 FERREIRA, Maria Gabriela Silva Campos. O compartilhamento de competências no processo civil: um estudo do sistema de competência sob o paradigma da cooperação judiciária. Salvador: JusPodivm, 2020, p. 195. 
ato de cooperação a ser praticado". Como apontado no dispositivo, essa intervenção será tão mais necessária quanto mais complexo for seu objeto.

Dessa forma, quando a cooperação tratar, por exemplo, de um ato único e simples como a prestação de informações, a intervenção das partes pode se apresentar desnecessária, restringindo-se à manifestação sobre as informações trazidas aos autos. Porém, quando envolver um ato concertado que pode ser firmado por um período mais longo e para uma série indeterminada de atos, o envolvimento das partes na sua construção é imprescindível.

A provocação do juiz pelas partes para a realização de uma cooperação judiciária ou sua manifestação sobre os contornos que ela deva tomar quando a iniciativa for dos próprios magistrados, ainda que em alguns casos prescindível, deve ser incentivada.

A participação da parte é relevante, pois as questões por ela trazidas aos debates preliminares à construção da cooperação podem antecipar problemas não cogitados pelos juízes cooperantes e, com isso, evitar problemas decorrentes de sua frustração em função da constatação superveniente de obstáculos. O desfazimento de uma cooperação judiciária já iniciada prejudicará a celeridade e a eficiência, uma vez que os atos poderão ter que ser refeitos e, com isso, a finalidade do artigo 69 , § 2.․, do CPC irá se perder.

A despeito da forma ou da intensidade da participação das partes, o certo é que elas não devem ser ignoradas ou excluídas da construção e da efetivação da cooperação judiciária. Quanto mais participativo for o desenvolvimento da cooperação, maior será sua capacidade de êxito. ${ }^{19}$ Destaquese que essa participação não deve restringir-se ao início da cooperação, as partes devem ser incluídas também nas discussões supervenientes que surjam no decorrer da cooperação.

Esse diálogo pode efetivar-se, por exemplo, pela intimação das partes para que se manifestem sobre o pedido de cooperação jurisdicional apresentado pelo juiz ou sobre o concerto entre os magistrados. Pode também envolver a realização de uma audiência conjunta entre os juízos cooperantes e as partes dos processos envolvidos para a definição da forma e dos limites da cooperação. A Resolução n.. $350 / 20$ do CNJ, em seu art. $8^{\circ}$, § $3^{\circ}$, prevê a possibilidade de as partes requererem esclarecimentos e solicitarem ajustes, na forma do artigo $357, \S 1^{\circ}$, do CPC.

Ressalte-se que isso não significa que a definição dos rumos da cooperação seja delegada às partes. ${ }^{20}$ A cooperação realiza-se em benefício da eficiência do processo ou dos processos, logo o interesse individual de uma das partes em um desfecho processual específico ou mesmo na demora na sua conclusão não pode prevalecer sobre o interesse na efetivação da prestação jurisdicional. As manifestações das partes devem ser analisadas pelo magistrado e ponderadas com base em uma lógica de eficiência processual e de efetividade da prestação jurisdicional, rejeitando-se aquelas que contrariarem os fundamentos e objetivos da cooperação.

Essa observação pode trazer a impressão de burocratização de um procedimento que é por natureza informal. Todavia, esse diálogo não é motivo de atraso ou de tumulto no seu desenvolvimento. Ao contrário, a ausência do debate pode ser causadora de problemas, em casos que levantem dúvida sobre a competência, em especial em situação de elevada resistência das partes. Se o objetivo maior é garantir eficiência à prestação da tutela jurisdicional, de nada adiantará uma cooperação se seu produto acarretar ampla discussão posterior, gerando incidentes que comprometam o andamento célere do processo.

19 Antonio do Passo Cabral destaca que: “[...] quanto mais aberta, transparente, participativa e previsível é a cooperação, menos resistência tende a gerar, até porque as partes podem se coordenar com a atividade judicial na condução do processo, e especificamente em relação à gestão da competência.” (CABRAL, 2017, p. 547).

20 Segundo Maria Gabriela Silva Campos Ferreira: "Os argumentos das partes deverão ser sopesados antes da decisão. Mas sem justificativa plausível, não haverá razão para se impedir a prática de ato de cooperação. A anuência das partes é dispensável para a concertação entre juízes". (FERREIRA, Maria Gabriela Silva Campos. O ato concertado entre juízes cooperantes: esboço de uma teoria para o Direito brasileiro Civil Procedure Review. v.10, n.3: set.-dez. 2019, p. 32). 


\section{Controle e impugnação da cooperação judiciária}

Alinhado aos fundamentos do tópico anterior, é preciso avaliar a possibilidade e a forma do controle e da impugnação da cooperação judiciária. A utilização tímida do instituto nos primeiros anos de vigência do CPC e os debates que ainda cercam os elementos essenciais do instituo colaboram para as dúvidas em torno desse tópico específico. Não se tem a pretensão de indicar aqui uma solução definitiva para o problema, mas existem orientações que já podem ser firmadas e aspectos que precisam começar a ser debatidos de forma mais direta.

Uma primeira diretriz que pode ser defendida é a de que esses atos são impugnáveis, pois podem conter irregularidades que precisam ser sanadas. A segunda diretriz é a de que existe interesse das partes e que a elas deve ser reconhecida legitimidade para a impugnação.

Esses dois primeiros aspectos foram contemplados de forma expressa na Resolução n.o 350/20 do $\mathrm{CNJ}$, primeiramente no art. 5ㅜㅡ, $\mathrm{V}$ que estabeleceu que a cooperação judiciária nacional "deve ser comunicada às partes do processo". Este dispositivo trata da publicidade do ato de cooperação judiciária já realizado, medida importante para viabilizar eventuais questionamentos que os interessados pretendam realizar.

De forma complementar e mais específica, o parágrafo único do art. 9º da Resolução n.․ 350/20 do CNJ estabelece que "os atos de cooperação poderão ser objeto de impugnação pelos meios previstos na legislação processual". Apesar do avanço em reconhecer a possibilidade de impugnação, a norma não detalha a forma pela qual ela ocorrerá. Esse é um sinal claro do estágio ainda embrionário do desenvolvimento desse aspectos específico da matéria.

Outro dispositivo da referida resolução que merece referência é o art. $5^{\circ}$, IV, que determina que a cooperação "deve ser realizada de forma fundamentada, objetiva e imparcial". A indicação da necessidade de apresentação de fundamentos de cunho objetivos abre caminho para uma dialeticidade, permitindo que à parte questionar os motivos apresentados como justificadores do ato.

Assim sendo, o direito à impugnação está resguardado, resta saber o que pode ser questionado e qual será a forma de efetivar tal impugnação. Para evoluir no entendimento desses pontos é preciso, mais uma vez distinguir, a cooperação judiciária dos atos processuais praticados a partir dela. Isso porque a cooperação judiciária em sí não decide qualquer questão relacionada ao mérito do conflito objeto do processo, somente estabelece a forma como os atos jurisdicionais serão praticados e, em alguns casos, a competência de quem os irá praticar. Dessa forma, ela se aproximará no máximo a decisões judiciais sobre o procedimento adotado, mas ainda assim com elas não se confundirá totalmente, pois a forma e o objetivo serão distintos. Portanto, o objeto da impugnação também não será o mesmo.

É certo que essa diferenciação nem sempre será clara, em determinadas situações manifestandose a cooperação judiciária e os atos jurisdicionais praticados a partir dela de forma quase simultânea e, algumas vezes, materializada no mesmo documento. É exatamente nessas situações que as dúvidas serão mais intensas. Em tais casos, em princípio, a saída mais segura é impugnar o próprio ato jurisdicionais pela via recursal, ou combater simultaneamente os dois aspectos do ato.

Feito este esclarecimento, passa-se a analisar as situações em que a distinção é mais evidente, para que se possa focar na impugnação dirigida especificamente à cooperação judiciária. Os instrumentos de cooperação não se enquadram nos pronunciamentos do juiz (art. 203 do CPC), pois possuem formas e finalidades diferentes.

Por exemplo, é possível celebrar um ato concertado para a centralização de processos repetitivos. Essa cooperação será previamente formalizada com a definição de seu objeto e a delimitação de sua abrangência, mas não implicará, por si só, em nenhum ato jurisdicional. Logo, o ato concertado pode existir prévia e independentemente das possíveis decisões que serão proferidas após sua formalização.

Assim sendo, a parte interessada poderá: I) impugnar a cooperação antes que dela decorram desdobramentos no processo; II) concordar com a cooperação, mas discordar do ato processual que dela decorreu e impugná-lo ou; III) impugnar tanto a cooperação judiciária como o ato dela decorrente. É 
importante ressaltar que essa divisão é feita com um objetivo didático, mas na prática serão várias as situações em que não será possível distingui-las.

Analisando as duas situações de forma isolada, passa-se inicialmente a abordar a impugnação dirigida a própria cooperação. O pedido de cooperação, a delegação, o ato concertado e outras possíveis formas de cooperação se manifestam como atos processuais, mas de cunho administrativo. Em certas situações, em especial nos atos concertados, a cooperação poderá inclusive assumir uma feição normativa, como por exemplo em um ato concertado destinado a distribuição de uma determinada matéria para um juízo específico. São ferramentas ligadas a questões de administração judiciária e não à solução direta de questões incidentais e finais do conflito objeto do processo.

Esse controle será da validade do ato de cooperação. No atual nível de maturidade da matéria é difícil estabelecer de forma precisa o objeto desse controle. Só a evolução da matéria com base em casos concretos poderá indicar quais são os limites da cooperação.

Nesses termos, os órgãos responsáveis pela análise das impugnações devem estar pautados primeiramente em formas de controle administrativo da atuação dos magistrados, o que pode se efetivar por meio de processos administrativos movidos perante a Presidência, a Corregedoria ou a órgão colegiado especificado no regimento do tribunal do tribunal. É bem verdade que, atualmente, os regramentos internos dos tribunais, na maior parte dos casos, não estão preparados para essas novas questões e talvez precisem evoluir para contemplar questões decorrentes da cooperação judiciária.

Ainda que não seja o caso de recurso, esse ato poderia ser, em tese, objeto de uma ação de conhecimento ou de um mandado de segurança quando aquela cooperação configurar de alguma forma ilegalidade ou abuso de poder.

Avançando na análise, passa-se a abordar as decisões judiciais decorrentes da cooperação. Destaque-se que as impugnações nesse ponto, ainda que interfiram indiretamente na cooperação, por abordar sua manifestação prática, não tem por objeto a própria cooperação.

As decisões judiciais devem ser combatidas pelas vias previstas no sistema processual, como por meio de recursos, da reclamação para preservação de competência, do conflito de competência, etc. A adequação e o cabimentos desses institutos não será, em princípio, tão clara e direta, pois eles não foram concebidos para tais situações. Somente com o amadurecimento do tema e com a ressignificação de alguns de seus elementos a nova realidade trazida pela cooperação judiciária será integrada harmônica ao sistema.

Quanto à utilização da via recursal, já se observa uma divergência doutrinária. Como os atos que formalizam a cooperação judiciária, em especial aquela que altere competência, podem se enquadrar no conceito de decisão interlocutória, cabe inicialmente analisar o cabimento do agravo de instrumento. Ocorre que o rol de decisões agraváveis do art. 1.015 do CPC não contempla de forma expressa as decisões acerca da competência.

Na concepção adotada pelo STJ para a interpretação do art. 1.015 do CPC, no contexto de uma "taxatividade mitigada", seria, em tese, possível enquadrar os casos de cooperação que envolvam alteração da competência no âmbito de recorribilidade do inciso III, que versa sobre a "rejeição da alegação de convenção de arbitragem" ${ }^{21}$.

No entanto, a complexa e confusa estrutura de recorribilidade das decisões interlocutórias não pode admitir uma ampliação ilimitada do cabimento do agravo de instrumento. Essa parece ser uma das situações que foge ao limite interpretativo da norma, de modo que, enquanto não sobrevier alteração

21 Na posição de Maria Gabriela Silva Campos Ferreira: “[...] defendemos ser possível a interposição de agravo de instrumento contra a decisão que alterar a competência para a prática de atos decisórios e instrutórios com base na cooperação entre juízes. Basta uma interpretação extensiva do art. 1.015, III do CPC que permite a impugnação das decisões que rejeitam convenção de arbitragem, já que ambas as decisões tratam sobre competência”. (FERREIRA, Maria Gabriela Silva Campos. O ato concertado entre juízes cooperantes: esboço de uma teoria para o Direito brasileiro Civil Procedure Review. v.10, n.3: set.-dez. 2019, p. 33). 
legislativa, tais decisões devem ser impugnadas por meio de apelação, conforme o $§ 1 .{ }^{\circ}$ do art. 1.009 do $\mathrm{CPC} / 15^{22}$.

\section{Conclusões}

O Código de Processo Civil estabelece o dever de cooperação para os magistrados o que importa que eles devem manter aberta uma via de contato para outros juízos e uma disponibilidade para prontamente atender as demandas de cooperação a eles submetidas. Esse dever, todavia, não é absoluta, ele admite a recusa fundamentada quando estiver presente uma causa justificadora idônea.

Há uma diferença de intensidade nesse dever de acordo com a maior ou menor possibilidade de recusa, manifestando-se mais forte na cooperação por concertação, seguida pela cooperação por delegação, e sendo menos intensa na cooperação por solicitação.

A resistência injustificada ou pautada em fundamento não aceito como legítimo por órgão com competência para essa análise configurará infração funcional nos termos do art. 35, I, da Lei Orgânica da Magistratura (Loman).

É preciso assegurar às partes canais de participação e de impugnação para viabilizar níveis de controle das cooperações, pois são elas que melhor conhecem conflito judicializado. O fato de a cooperação judiciária caber aos magistrados, não significa que se deva desconsiderar a posição das partes a seu respeito. Esse diálogo tornará a cooperação mais adequada e robusta.

\section{Referências}

CABRAL, Antonio do Passo. Juiz natural e eficiência processual: flexibilização, delegação e coordenação de competências no processo civil. 2017. Tese (Concurso de Titularidade) - Universidade do Estado do Rio de Janeiro, Rio de Janeiro, UERJ, 2017.

CAMARGO, Luiz Henrique Volpe. A centralização de processos como etapa necessária do incidente de resolução de demandas repetitivas. 2017. Tese (Doutorado em Direito) - Pontifícia Universidade Católica de São Paulo, São Paulo, 2017.

CHAVES JÚNIOR, José Eduardo de Resende. Cooperação judiciária na justiça do trabalho. Revista do Tribunal Regional do Trabalho da 3a Região, Belo Horizonte, v. 61, n. 92, p. 107-130, jul./dez. 2015 .

CRAMER, Ronaldo. Comentários ao art. 267. Comentários ao novo Código de Processo Civil. coordenação Antonio do Passo Cabral, Ronaldo Cramer. - 2a ed. Rio de Janeiro: Forense, 2016.

DIDIER JR. Fredie. Cooperação judiciária nacional: esboço de uma Teoria para o Direito Brasileiro. Salvador: Juspodivm, 2020.

FERREIRA, Maria Gabriela Silva Campos. O compartilhamento de competências no processo civil: um estudo do sistema de competência sob o paradigma da cooperação judiciária. Salvador: JusPodivm, 2020.

O ato concertado entre juizes cooperantes: esboço de uma teoria para o Direito brasileiro Civil Procedure Review. v.10, n.3: set.-dez. 2019.

FONSECA, João Gustado Henrique de Marais. Cooperação Judiciária processual: histórico, teoria e prática. Rio de Janeiro: Lumen Juris, 2019.

22 Edilton Meireles adota esse entendimento: "Ou seja, ainda que não imediatamente recorrível mediante agravo de instrumento, ela pode ser impugnada em apelação ao final da fase de conhecimento (§ 1. do art. 1.009 do CPC/2015). (MEIRELES, Edilton. Cooperação judiciária nacional. Revista de Processo. v. 249. nov. 2015. pp. 59-80, p. 70). 
GAJARDONI, Fernando da Fonseca; DELLORE, Luiz; ROQUE, Andre Vasconcelos; OLIVEIRA JR., Zulmar Duarte de. Teoria Geral do Processo: parte geral: comentários ao CPC de 2015. 3. ed. Rio de Janeiro: Forense; São Paulo: MÉTODO, 2019.

MARINONI, Luiz Guilherme; ARENHART, Sérgio Cruz; MITIDIERO, Daniel. Novo curso de processo civil: tutela dos direitos mediante procedimentos comum. $3^{\underline{a}}$ Ed. São Paulo, Editora dos Tribunais, 2017.

MEIRELES, Edilton. Cooperação judiciária nacional. Revista de Processo. v. 249. nov. 2015. pp. 59-80. . Cooperação judicial e poderes do juiz na execução conforme o CPC de 2015. Revista Jurídica Luso-Brasileira, Lisboa, ano 4, n. 1, p. 455-507, 2018.

PASSOS, Jose Joaquim Calmon de. Ensaios e artigos - V.1. Salvador: JusPodivm, 2014. JusPodivm, 2012. . Revisitando o Direito, o Poder, a Justiça e o Processo. Salvador: 